\title{
Activity of Centrally Administered Galanin Fragments on Stimulation of Feeding Behavior and on Galanin Receptor Binding in the Rat Hypothalamus
}

\author{
Jacqueline N. Crawley, ${ }^{1}$ Mark C. Austin, ${ }^{1}$ Susan M. Fiske, ${ }^{1}$ Brian Martin, ${ }^{1}$ Silvana Consolo, ${ }^{2}$ Malin Berthold, ${ }^{3}$

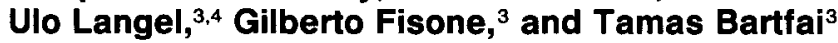 \\ 'Clinical Neuroscience Branch, National Institute of Mental Health, Bethesda, Maryland 20892, 2Istituto di Richerche \\ Farmacologiche "Mario Negri," Milano, Italy, "Department of Biochemistry, University of Stockholm, Sweden, and \\ ${ }^{4}$ University of Tartu, Estonian S.S.R.
}

\begin{abstract}
Synthetic fragments of galanin 1-29 were administered intraventricularly or into the paraventricular nucleus of the hypothalamus for analysis of the critical amino acid sequence necessary to stimulate feeding behavior in rats. Galanin 1-29 and galanin fragment 1-16 significantly increased feeding at doses of $6 \mathrm{nmol}$ microinjected into the lateral ventricles and $1 \mathrm{nmol}$ microinjected into the hypothalamus. There was no significant effect of $D-T R P^{2}$ galanin 1-16 microinjected into the hypothalamus, and no significant effect of galanin fragments $1-9,10-20,12-29,17-29$, or $21-29$ microinjected intraventricularly, on food consumption. Synthetic fragments of galanin 1-29 were assayed for displacement of ${ }^{125}$ /-galanin 1-29 binding to rat hypothalamic membranes. The efficacies of the galanin fragments in the feeding paradigm were consistent with the relative affinities of these fragments for the hypothalamic galanin receptor in equilibrium binding experiments. The first $16 \mathrm{~N}$-terminal amino acids appear to contain galanin agonist activity on increasing food consumption and to bind to the galanin receptor in the rat hypothalamus.
\end{abstract}

Galanin is a 29 -amino acid peptide isolated from the porcine intestine (Tatemoto et al., 1983) and localized in the mammalian CNS (Skofitsch and Jacobowitz, 1985; Melander et al,, 1986). Physiological actions of peripherally administered galanin include contraction of smooth muscle (Ekblad et al., 1989), activation of an ATP-dependent potassium channel (de Weille et al., 1988), and inhibition of glucose-stimulated insulin release (McDonald et al., 1985; Leonhardt et al., 1989). Galanin has been found to elevate circulating levels of growth hormone (Ottlecz et al., 1988; Murakami et al., 1987) and prolactin (Koshiyama et al., 1987), to inhibit dopamine release from the median eminence (Nordström et al., 1987), to inhibit ACh release from the hippocampus (Fisone et al., 1987), and to inhibit norepinephrine release from the hypothalamus (Tsuda et al., 1989). Other reported central effects of galanin include inhibition of slow cholinergic excitatory postsynaptic potentials in the hippocampus (Dutar et al., 1989), inhibition of locus coeruleus

\footnotetext{
Received Apr. 9, 1990; revised July 2, 1990; accepted July 18, 1990.

We wish to thank Dr. Sarah Leibowitz for extremely helpful advice in establishing the galanin-induced feeding paradigm in our laboratory.

Correspondence should be addressed to Jacqueline N. Crawley, Ph.D., Chief, Unit on Behavioral Neuropharmacology, Clinical Neuroscience Branch, National Institute of Mental Health, Building 10 Room 4N214, Bethesda, MD 20892.

Copyright (c) 1990 Society for Neuroscience 0270-6474/90/113695-06\$03.00/0
}

firing (Seutin et al., 1989), inhibition of noradrenergic stimulation of cAMP production in the cerebral cortex (Nishibori et al., 1988), inhibition of carbachol-stimulated phosphatidyl inositol hydrolysis in the ventral hippocampus (Palazzi et al., 1988), and modulation of binding to the serotonin $1 \mathrm{~A}$ receptor in the ventral limbic cortex (Fuxe et al., 1988). These diverse findings implicate galanin in inhibitory modulation of several central neurotransmitters, in initiating the release of pituitary hormones, and in the regulation of food consumption and metabolism both centrally and peripherally.

Behavioral actions of centrally administered galanin include inhibition of ACh-induced improvement of performance on a t-maze delayed alternation task in rats with basal forebrain lesions (Mastropaolo et al., 1988), inhibition of acquisition of a Morris swim-maze task (Sundström et al., 1988), inhibition of head twitches induced by a serotonin- 2 agonist (Ögren and Fuxe, 1989), induction of feeding (Kyrkouli et al., 1986), and inhibition of the flexor spinal reflex (Wiesenfeld-Hallin et al., 1989).

Galanin thus appears to have a variety of biological actions at several anatomical sites in the brain and in the periphery (Rökaeus, 1987). It would be of interest, therefore, to determine the amino acid sequence within galanin 1-29 that is critical for its biological activity and to determine whether this sequence differs at central versus peripheral sites. Induction of feeding provides a useful screen for evaluating the central activity of putative galanin analogues and antagonists. Porcine galanin 1-29 microinjected into the paraventricular nucleus of the hypothalamus (PVN) has been demonstrated to stimulate food consumption in satiated rats (Kyrkouli et al., 1986). Galanin appears to increase preferentially the consumption of a high-fat diet, as compared to a high-protein or a high-carbohydrate diet (Tempel et al., 1988). These actions of galanin in the PVN may be mediated through stimulation of norepinephrine release, because galanin microinjected into the PVN significantly increased extracellular norepinephrine in the PVN (Kyrkouli et al., 1988, 1990). The present study was designed to analyze a series of fragments of galanin 1-29 on the induction of feeding after central administration to the laboratory rat, and on displacement of ${ }^{125}$ I-galanin 1-29 binding in rat hypothalamic membranes, in a first attempt to identify the amino acid sequence within galanin 1-29 that delineates the behavioral activity of this neuropeptide.

\section{Materials and Methods}

Animals. Male Sprague-Dawley rats, 250-300 gm, were housed in a temperature- and humidity-controlled vivarium, lights on 7 AM through 
7 PM, with rat chow and water available ad libitum. On the evening before the first feeding experiment, each rat was given 1 Nilla wafer cookie (Nabisco Brands, Inc., East Hanover, NJ) soaked in $5 \mathrm{ml}$ distilled water, in a plastic weighing cup, which remained in the home cage overnight. Cookie mash was chosen as a highly palatable food, high in fat content, which rats consume readily after a single overnight habituation, to prevent food ncophobia (Crawley and Kiss, 1985).

Surgery. Implantation of indwelling guide cannulae was performed under chloral hydrate anesthesia, using stereotaxic coordinates according to Paxinos and Watson (1986). Intraventricular coordinates were $1.0 \mathrm{~mm}$ caudal and $1.0 \mathrm{~mm}$ lateral to the bregma and $3 \mathrm{~mm}$ ventral to the surface of the skull, cannulated unilaterally. Coordinates for the paraventricular nucleus of the hypothalamus were $1.8 \mathrm{~mm}$ caudal and $0.4 \mathrm{~mm}$ lateral to the bregma, $7.0 \mathrm{~mm}$ ventral to the skull surface, mouthbar at $-3.2 \mathrm{~mm}$, cannulated bilaterally. One week after surgery, microinjections were performed through a 31 -gauge stainless-steel hypodermic injection tube extending $1.0 \mathrm{~mm}$ below the ventral surface of the guide cannula. Unilateral intraventricular injections were $5 \mu \mathrm{lol}$, $1 \mu \mathrm{l}$ every $5 \mathrm{sec}$, with the injection tube remaining in place for an additional $40 \mathrm{sec}$. Bilateral PVN injections were $0.3 \mu \mathrm{l}$ vol, over a 47 scc pcriod, using a Sage microinfusion pump (Orion Instruments, Cambridge, MA), with the injection tube remaining in place for an additional $30 \mathrm{sec}$.

Feeding test. Immediately after injection, the rat was placed in a clean cage containing 2 Nilla wafer cookies soaked in $10 \mathrm{ml}$ distilled water, in a plastic weighing cup, for a 30 -min period. The weight of the cookie mash was recorded before and after the 30-min feeding session. Consumption was calculated as the difference in weights before and after the session.

Statistical analysis. Food consumption was evaluated for each dose of each galanin fragment in comparison to that obtained after microinjection of vehicle. Statistical significance of peptide effects within a given series of vehicle, galanin, and fragments was evaluated by 1 -way analysis of variance (ANOVA), followed by Newman-Keuls or Dunnett's test for significance of individual means. Each animal was used twice, with 1 week between the first and second uses and with treatments randomized such that each animal received a different treatment on the first and on the second use.

Histological analysis. At the end of each experiment, rats cannulated in the PVN were killed for histological analysis of the location of the injection sites. Brains were removed, stored in $8 \%$ formalin, sectioned at $100 \mu \mathrm{m}$, stained with thionin, and analyzed by light microscopy. Data from animals with one or both cannulae outside of the PVN were eliminated from statistical analyses. Some brains from animals cannulated in the lateral ventricle were removed and similarly analyzed histologically for location of the injection site.

Peptides. Galanin 1-29, porcine and rat, was obtained from Bachem Bioscience Inc. (Philadelphia, PA) and from Bachem Fine Chemicals (Torrance, CA). Porcine and rat galanin 1-29 from both suppliers were tested intraventricularly and found to be equivalent in stimulation of feeding.

Fragments of galanin 1-29 were prepared by enzymatic cleavage or by solid-phase synthesis. Galanin fragments 1-9 and 10-20 were prepared by tryptic digestion of synthetic porcine galanin 1-29 (Bachem, Torrance, CA). Fragments $1-9$ and 10-20 were obtained after digesting $700 \mu$ g galanin $1-29$ in $1 \mathrm{ml}$ of $50 \mathrm{~mm}$ Tris- $\mathrm{HCl}(\mathrm{pH}, 8.0)$ with $14 \mu \mathrm{g}$ DPCC trypsin (Sigma Chemical Co., St. Louis, MO) for $4 \mathrm{hr}$ at $37^{\circ} \mathrm{C}$. Galanin 1-16 was prepared by endoproteinase Asp- $N$ digestion as previously described (Fisone et al., 1989a). Peptides were purified by reverse-phase (C-18) high-pressure liquid chromatography and characterized by amino acid sequence analysis.

Galanin fragments 12-29, 17-29, 21-29, a second batch of galanin $1-16$, and D-TRP' $1-16$ wcre synthesized manually on $p$-methylbenzhydrylamine resin $(0.35 \mathrm{mmol} / \mathrm{gm})$. Protected $t$-butoxycarbonyl amino acids were serine (benzyl-), threonine (benzyl-), tyrosine ( $p$-bromobenzyloxycarbonyl-), histidine (dinitrophenyl-), and D- and L-tryptophan (formyl-). Asparagine and glutamine were coupled as active hydroxybenzotriazole esters. All other amino acids were activated by $N, N^{\prime}$ dicyclohexylcarbodiimide in a molar ratio of $1: 1$. The protocol for stepwise solid-phase peptide synthesis using the $t$-butoxycarbonyl-benzyl protective group strategy has been published elsewhere (Tam and Merrifield, 1985). Removal of protection was carried out by low trifluoromethanesulfonic acid (Tam, 1985), and the resin was washed with trifluoroacetic acid $(2 \times 1 \mathrm{~min})$, dichloromethane $(3 \times 1 \mathrm{~min})$, dimethylformamide $(3 \times 1 \mathrm{~min})$, ethanol $(2 \times 1 \mathrm{~min})$, and diethyl ether $(1 \times$
$1 \mathrm{~min}$ ). The resin was dried under vacuum followed by final removal of protection by hydrogen fluoride containing $8 \% p$-cresol and $2 \%$ ethanedithiol at $0^{\circ} \mathrm{C}$ for $40 \mathrm{~min}$. Purification of the cleaved peptides was carried out by high-pressure liquid chromatography on a C-18 reversephase column.

For intraventricular experiments, galanin 1-29 and fragments were dissolved in a vehiclc of $0.9 \%$ physiological saline. For PVN experiments, galanin 1-29 and fragments were dissolved in Ringer's vehicle (S. E. Kyrkouli and S. F. Leibowitz, personal communication). For all experiments with galanin and fragments, lyophylized peptide was dissolved, aliquoted, and stored at $-20^{\circ} \mathrm{C}$. Each aliquot was defrosted only on the day of use, and the excess was discarded.

Preparation of the radioligand ${ }^{225}$ I-galanin. Preparation of the radioligand ${ }^{125}$ I-galanin was performed by iodination of porcine galanin at room temperature by the chloramine-T method. Galanin. $10 \mu \mathrm{g}$. in 20 $\mu 10.05 \mathrm{M}$ sodium phosphate buffer $(\mathrm{pH} 7.5)$ and $20 \mu$ l chloramine-T (5 $\mathrm{mg} / \mathrm{ml})$ were added in a batch containing $2 \mathrm{mCi} \mathrm{Na}{ }^{125} \mathrm{I}(245 \mathrm{mCi} / \mathrm{ml})$. The reaction was terminated by adding $100 \mu \mathrm{l}$ of a solution of sodium metabisulfite $(1.2 \mathrm{mg} / \mathrm{ml})$. The reaction mixture was transferred onto a column packed with SP-Sephadex C25, equilibrated with a solution of $100 \mathrm{mg} / \mathrm{ml} \mathrm{BSA}$, then washed and equilibrated with $0.05 \mathrm{M}$ sodium phosphate buffer $(\mathrm{pH}, 5.0)$. The excess $\mathrm{Na}^{25 I}$ was first eluted with a $0.05 \mathrm{M}$ sodium phosphate buffer $(\mathrm{pH}, 5.0)$, while the iodinated galanin was eluted as a single peak with $0.05 \mathrm{M}$ sodium phosphate buffer $(\mathrm{pH}$, 8.1). Fractions corresponding to a peak of ${ }^{125}$ I-galanin were pooled, the $\mathrm{pH}$ adjusted to 6.0 with acetic acid, and the aliquots stored at $-18^{\circ} \mathrm{C}$ until use.

Preparation of membranes. Rat brains were quickly removed and the hypothalamus dissected for preparation of membranes. The tissue was homogenized $(10 \%$ mass/vol) in $0.32 \mathrm{M}$ sucrose buffered with $5 \mathrm{~mm}$ HEPES (pH, 7.4). The homogenate was diluted 10 -fold and centrifuged at $1000 \times g$ for $10 \mathrm{~min}$. The supernatant was centrifuged at $10,000 \times g$ for $45 \mathrm{~min}$, and the pellet was resuspended in $5 \mathrm{mM}$ HEPES-buffered Krebs-Ringer solution ( $\mathrm{pH}, 7.4)$. All displacement curves were compriscd of 24 or more independent observations taken at 8 different concentrations. Protein concentration was determined according to the Lowry method, using BSA as a standard.

Ligand-binding studies. Displacement experiments were carried out in a final volume of $400 \mu 15 \mathrm{~mm}$ HEPES/Krebs-Ringer solution, $0.05 \%$ BSA (pH, 7.4), containing $1 \mathrm{~mm}$ porcine ${ }^{125}$ I-galanin and $70-100 \mu \mathrm{g}$ membrane preparation. Samples were incubated for $30 \mathrm{~min}$ at $37^{\circ} \mathrm{C}$. Incubation was terminated by the addition of $10 \mathrm{ml}$ ice-cold HEPES/ Krebs-Ringer solution, followed by rapid filtration over Whatman GF/B filters, precoated for $5-6 \mathrm{hr}$ in $0.3 \%$ polyethyleneimine solution. Specific binding was defined as that displaceable by $1 \mu \mathrm{M}$ rat galanin 1-29.

\section{Results}

Figure 1 shows the effects of intraventricularly administered galanin 1-29 and N-terminal galanin fragments 1-9 and 1-16, at a dose of $6 \mathrm{nmol} / 5 \mu \mathrm{l}$, on consumption of a palatable food. As compared to values obtained after saline vehicle alone, galanin 1-29 and galanin 1-16 significantly increased food consumption (ANOVA $F_{3,75}=18.47, p<0.001$; Newman-Keuls $p<0.01$ for $1-29, p<0.05$ for 1-16, NS for 1-9).

Figure 2 shows the effects of intraventricularly administered galanin 1-29 and C-terminal galanin fragments 12-29, 17-29, 21-29, and 10-20, at a dose of $6 \mathrm{nmol} / 5 \mu 1$, on food consumption. As compared to values obtained after saline vehicle alone, only galanin 1-29 significantly increased feeding (ANOVA $F_{5,69}=$ $7.74, p<0.001$; Newman-Keuls $p<0.01$ for $1-29$, NS for 12 29, 17-29, 21-29, and 10-20).

Figure 3 illustrates the placement of bilateral cannulae and injection sites in the PVN. Data from 7 animals were eliminated from statistical analyses because of histological evidence for one or both injection sites being outside of the PVN.

Figure 4 shows the effects of galanin 1-29, galanin 1-16, and D-TRP ${ }^{2}$-galanin 1-16 on food consumption after microinjection into the PVN. As compared to values obtained after Ringer's vehicle alone, galanin 1-29 and galanin 1-16 significantly in- 


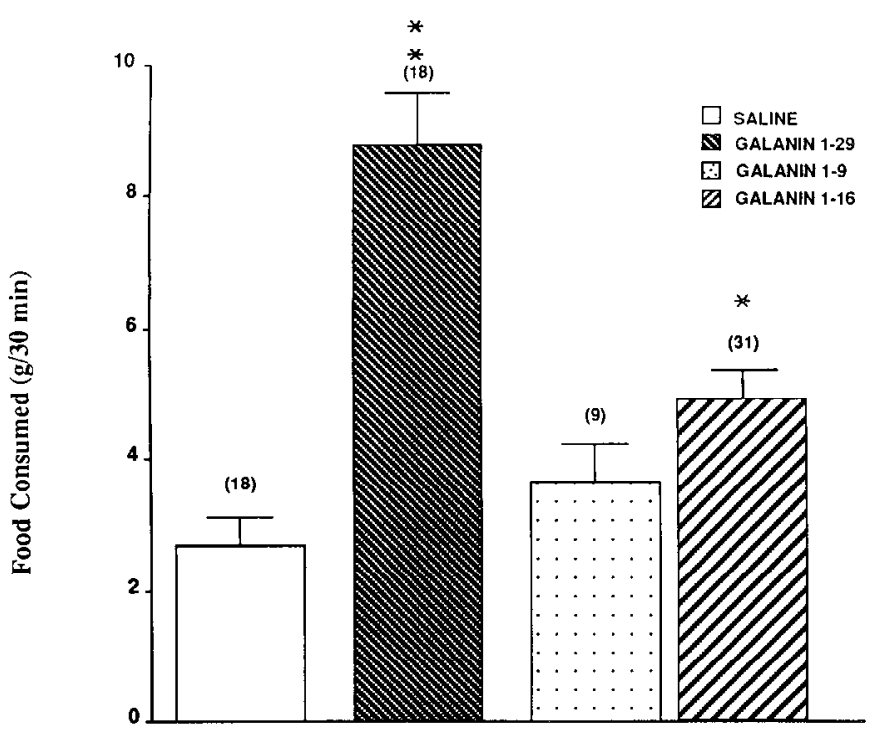

Treatment ( 6 nmoles)

Figure 1. Comparison of food consumption after intraventricular microinjection of saline, galanin 1-29, and N-terminal galanin fragments 1-9 and 1-16. Each peptide was administered at a dose of $6 \mathrm{nmol}$ in a vol of $5 \mu \mathrm{l}$ over a 1 -min period. Consumption of a palatable cookie mash over a $30-$ min period immediately after microinjection was significantly elevated after galanin 1-29 $\left({ }^{* *}, p<0.01\right)$ and after galanin 1-16 $\left(^{*}, p<0.05\right)$, as compared to saline-vehicle control values. Data are expressed as mean + SEM. Number of animals is shown in parentheses for each treatment group.

creased feeding (ANOVA $F_{6.29}=18.17, p<0.001$; Dunnett's test $p<0.05$ for galanin $1-29$ at a dose of $0.5 \mathrm{nmol}, p<0.01$ for galanin 1-29 at $1 \mathrm{nmol}, p<0.01$ for galanin $1-16$ at $1 \mathrm{nmol}$ ). There was no significant effect of galanin 1-16 at the dose of 0.5 $\mathrm{nmol}$, nor of D-TRP2 $1-16$ at $1 \mathrm{nmol}$. There was no significant difference in food consumption between animals receiving vehicle microinjection alone and animals receiving no microinjection.

Behavioral data from 7 animals in the PVN experiments were excluded from the statistical analysis presented above after histological analyses revealed cannulae placements outside of the PVN. Animals with both cannulae placements dorsal, ventral, or rostral to the PVN showed no increase in food consumption after microinjection of galanin 1-29. Animals with one cannula placed within the PVN but the other cannula medial or dorsal to the PVN showed partial responses to galanin 1-29 on food consumption.

Figure 5 shows the displacement of ${ }^{125}$ I-galanin 1-29 from hypothalamic binding sitcs by increasing concentrations of galanin fragments. Galanin 1-16 displaced radioligand binding with a $K_{D}$ of 8.2 nM. D-TRP ${ }^{2}$ galanin 1-16, galanin 17-29, and galanin 21-29 did not displace radioligand binding in the nanomolar range of concentrations.

\section{Discussion}

The present data demonstrate that an N-terminal fragment of galanin, 1-16, stimulates food consumption in a manner similar to stimulation of food consumption by the full-length sequence, 1-29. When administered into the lateral ventricle, galanin fragment $1-16$ was approximately $1 / 3$ as potent as galanin $1-29$. When administered into the PVN, galanin fragment 1-16 was approx-

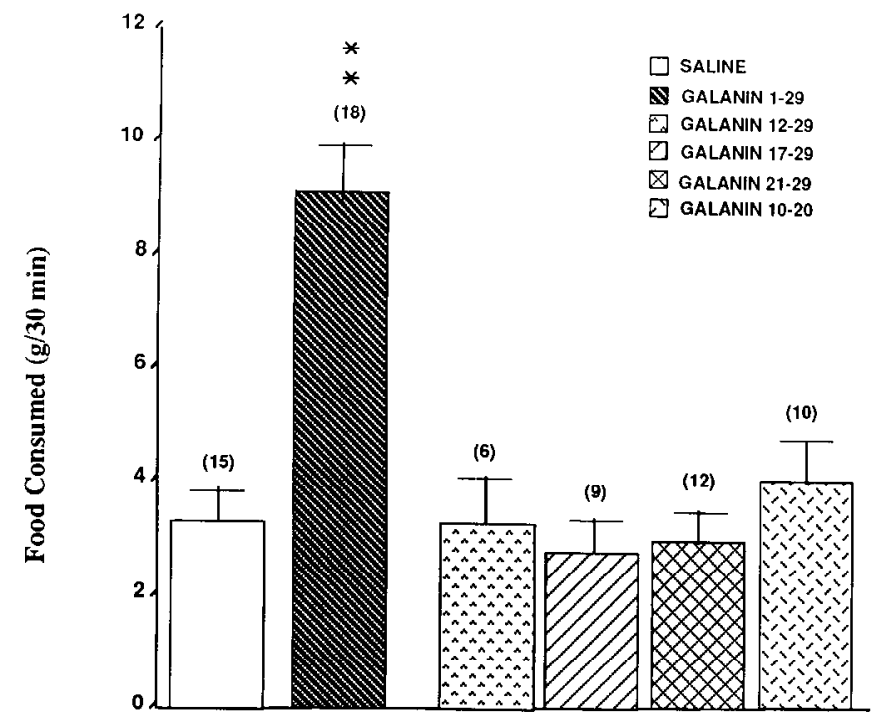

Treatment ( 6 nmoles)

Figure 2. Comparison of food consumption after intraventricular microinjection of saline, galanin 1-29, and C-terminal galanin fragments 12-29, 17-29, 21-29, and 10-20. Each peptide was administered at a dose of $6 \mathrm{nmol} / 5 \mu \mathrm{l}$. Food consumption was assayed and analyzed as described in Figure 1. Consumption was significantly elevated only after galanin 1-29 $(* *, p<0.01)$ as compared to saline-vehicle control values. Data are expressed as mean + SEM. Number of animals is shown in parentheses for each treatment group.

imately half as potent as galanin 1-29. Binding experiments with hypothalamic membranes found that the rank order of efficacy of several galanin fragments for displacement of ${ }^{125}$ I-galanin 1-29 binding coincided with the rank order of their efficacy in inducing food consumption after PVN microinjection. These results support an interpretation that the actions of galanin 1-29 and galanin 1-16 on feeding behavior are mediated by the hypothalamic galanin receptor.

Substitution of a D-TRP for the L-TRP amino acid in the number 2 position of galanin 1-16 produced a relatively inactive fragment in both the feeding behavior and the receptor binding assays, suggesting that the second amino acid at the N-terminal is critical for biological activity in the present paradigms. Lack of activity of the 1-9 fragment on feeding behavior suggests that the minimum amino acid sequence necessary for biological activity in the present paradigm is longer than the first 9 amino acids. Lack of activity of the 10-20, 12-29, 17-29, and 21-29 fragments on feeding behavior, at doses equimolar to the active dose of 1-29 and of 1-16, suggests that the C-terminal end of galanin 1-29 is less critical for induction of feeding behaviors.

Another explanation for the lack of activity of some of the galanin fragments might be a rapid metabolic degradation in vivo. In the case of the active fragment, 1-16, where the increase in feeding was less than the increase in feeding after galanin 1-29 at comparable molar doses, reduced potency could reflect a more rapid breakdown of 1-16 after microinjection. The increase in feeding after 1-16 was greater after administration into the PVN than after administration into the lateral ventricles, possibly indicating degradation in the cerebrospinal fluid as the peptide traveled from the lateral ventricle to the hypothalamus. Alternatively, the lesser effects of $1-16$ could reflect a reduced efficacy. C-terminal portions of the tertiary structure of galanin 1-29 may be necessary for initiation of the maximal biological 


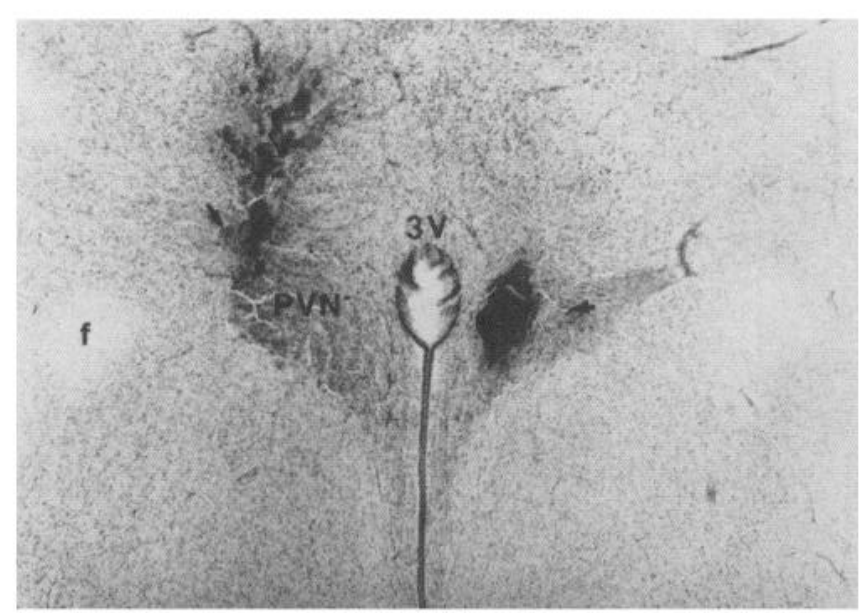

Figure 3. Representative photomicrograph of bilateral cannula placements in PVN. Arrows indicate microinjection sites. $F$, fornix; $3 \mathrm{~V}$, third ventricle. Magnification, $31 \times$.

response at the central galanin receptor. A third possibility that may explain the apparently lower efficacy of fragment 1-16 is that the N-terminal fragment is more hydrophobic than the fulllength peptide, and may be adsorbed nonspecifically. This greater hydrophobicity may make the $\mathrm{N}$-terminal fragments interesting with respect to penetration into the brain when tested by systemic administration.

The finding that galanin 1-16 is an agonist in the hypothalamus is consistent with the recent report by Fisone et al. (1989a) that galanin 1-16 displaced ${ }^{125} \mathrm{I}$-labeled galanin binding in the rat ventral hippocampus and spinal cord, that galanin 1-16 inhibited carbachol-stimulated phosphatidyl inositol hydrolysis in the ventral hippocampus, and that intraventricularly administered galanin 1-16 inhibited scopolamine-induced release of $\mathrm{ACh}$ from the ventral hippocampus in vivo. In addition, substitution of $\mathrm{L}_{-} \mathrm{TRP}^{2}$ by $\mathrm{D}-\mathrm{TRP}^{2}$ in galanin 1-16 produced a loss in activity in displacement of ${ }^{125} \mathrm{I}$-galanin binding in the ventral hippocampus (Fisone et al., 1989a), consistent with the present behavioral and receptor-binding data in the hypothalamus.

Bioassays in the PNS have shown a profile of galanin-fragment activity with similarities to the present data. N-terminal activity has been shown by galanin fragments 1-10 (Ekblad et al., 1989) and 1-20 (Fox et al., 1988) on smooth muscle contraction, by 2-29 and 1-15 on insulin release from the pancreas (Amiranoff et al., 1989; Hermansen et al., 1989), and by 2-29 and 1-15 on displacement of binding to pancreatic galanin receptors (Hermansen et al., 1989; Lagny-Pourmir et al., 1989). In these studies, fragments lacking the first 2 amino acids from the $\mathrm{N}$-terminal (e.g., 3-29) were without effect (Amiranoff et al., 1989; Hermansen et al., 1989), and fragments from the C-terminal of the peptide, including $9-29,10-29$, and $15-29$, were relatively inactive (Amiranoff et al., 1989; Hermansen et al., 1989; Rossowski and Coy, 1989). Studies with galanin fragments in the CNS have shown some activity in displacing ${ }^{125}$ I-galanin 1-29 binding at micromolar concentrations by C-terminal fragments such as $12-29,15-29,18-29$, and 21-29, though N-terminal fragments such as $1-15$ and $1-16$ were considerably more potent (Gabriel et al., 1988; Fisone et al., 1989b; Lagny-Pourmir et al., 1989). Potential differences in galanin fragments that are active in the peripheral versus the central nervous systems may indicate differences in galanin-receptor subtypes in the periphery versus in the brain and/or different routes of metabolism of galanin and its fragments in the periphery versus the brain. It is also interesting to speculate that the peripheral action of gal-

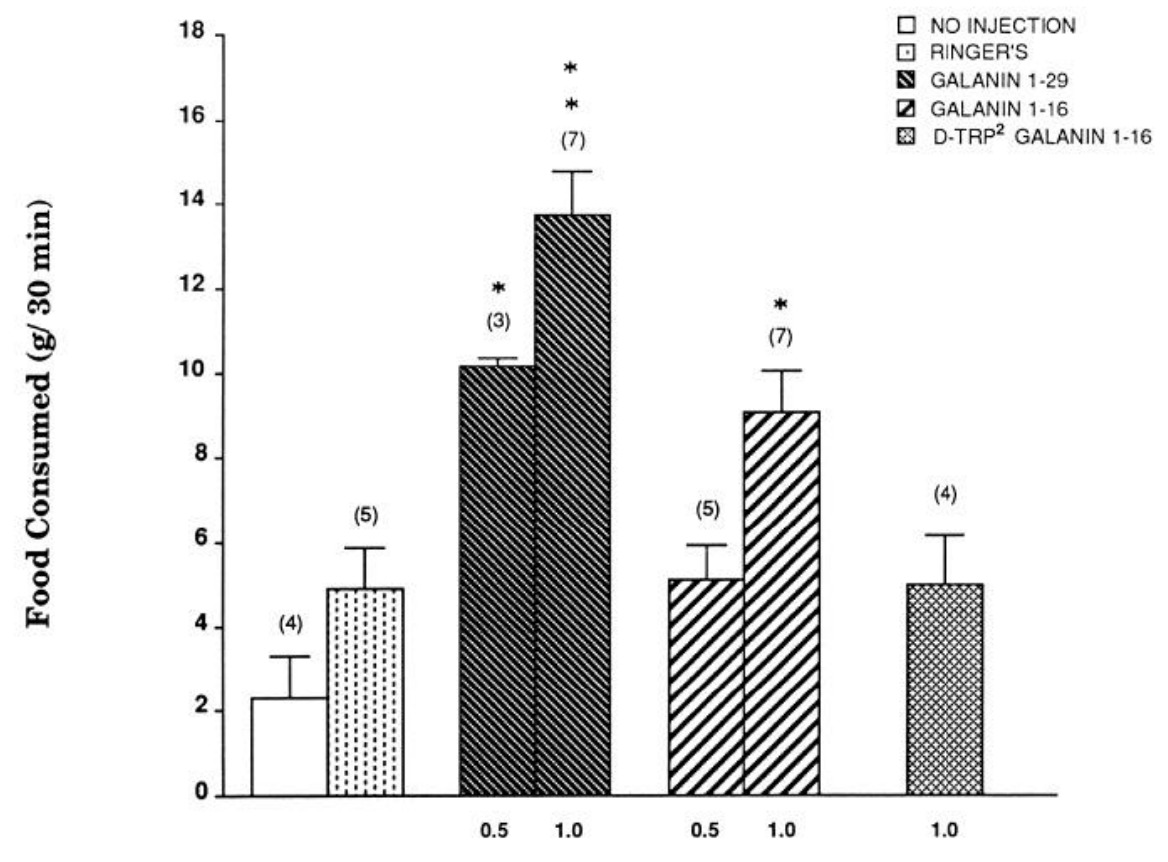

\section{Dose (nmoles)}

Figure 4. Comparison of food consumption after microinjection of Ringer's solution, galanin 1-29, galanin 1-16, or galanin D-TRP2 1-16 into the PVN. Consumption of cookie mash over a 30-min period was significantly elevated after galanin $1-29\left(*, p<0.05\right.$ at a dose of $0.5 \mathrm{nmol} ;{ }^{* *}$, $p<0.01$ at $1.0 \mathrm{nmol})$ and after galanin $1-16\left({ }^{*}, p<0.05\right.$ at $\left.1.0 \mathrm{nmol}\right)$, as compared to Ringer's vehicle control values. A lower dose of galanin 1-16 $(0.5 \mathrm{nmol})$ and the D-TRP ${ }^{2}$-substituted galanin $1-16$ at $1.0 \mathrm{nmol}$ had no significant effect on food consumption. Data are expressed as mean + SEM. Number of animals is shown in parentheses for each treatment group. 


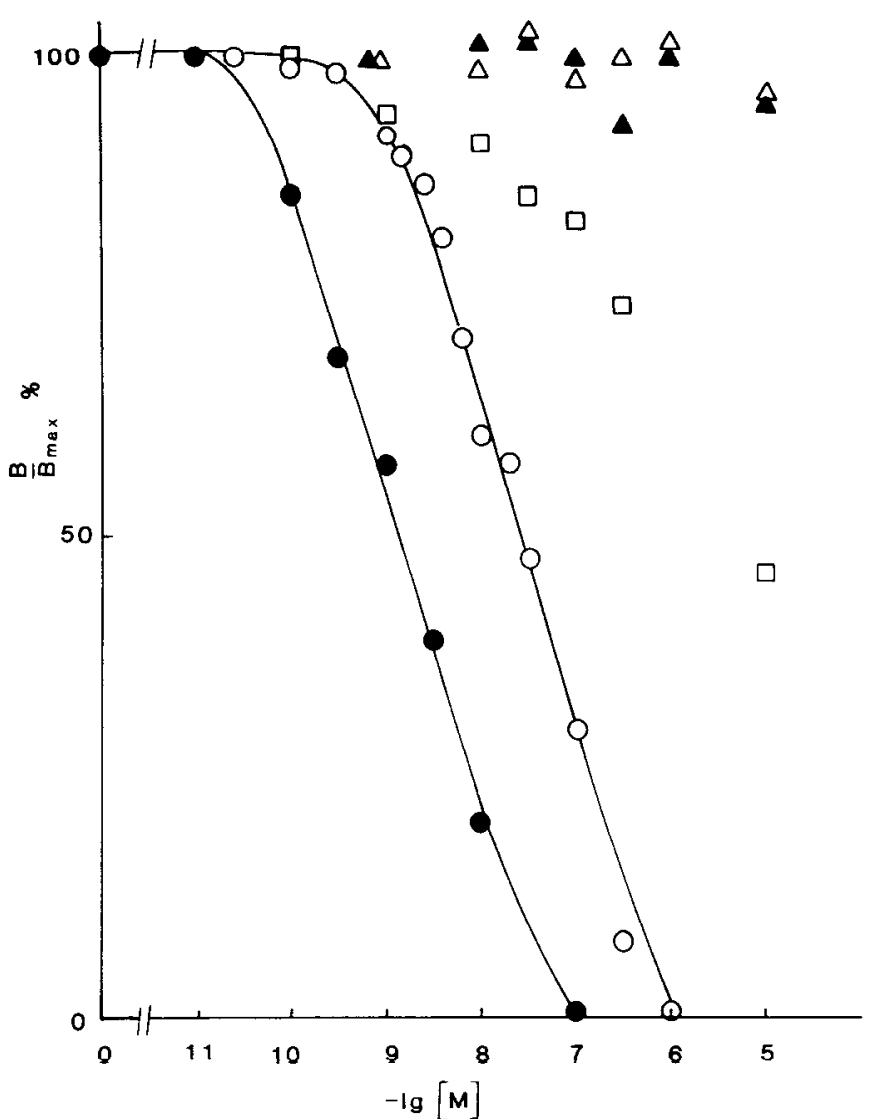

Figure 5. Displacement of ${ }^{125} \mathrm{I}$-galanin (porcine, $1 \mathrm{nM}$ ) from binding sites in membranes from rat hypothalamus by galanin 1-29 (solid circles) and by galanin fragments 1-16 (open circles), D-TRP 1 1-16 (open squares), 17-29 (open triangles), and 21-29 (solid triangles). Each point is measured in triplicate.

anin in inhibiting glucose-stimulated insulin release (McDonald et al., 1985; Leonhardt et al., 1989) may be functionally linked to the central action of galanin in stimulating consumption of a high-fat diet (Tempel et al., 1988).

In conclusion, data from a behavioral assay of galanin fragments, from the induction of feeding after central administration, and from binding data using rat hypothalamic membranes suggest that the $\mathrm{N}$-terminal 16 amino acids contain agonist activity at the hypothalamic galanin receptor. This finding may provide useful information for the development of potent, selective galanin agonists and antagonists to further investigate the role of endogenous galanin in biological functions.

\section{References}

Amiranoff B, Lorinet AM, Yanaihara N, Laburthe M (1989) Structural requirements for galanin action in the pancreatic $B$ cell line $R$ in $m$ 5F. Eur J Pharmacol 163:205-207.

Crawley JN, Kiss JZ (1985) Paraventricular nucleus lesions abolish the inhibition of feeding induced by systemic cholecystokinin. Peptides 6:927-935.

de Weille J, Schmid-Antomarchi H, Fosset M, Lazdunski M (1988) ATP-sensitive $K$ ' channels that are blocked by hypoglycemia-inducing sulfonylureas in insulin-secreting cells are activated by galanin, a hyperglycemia-inducing hormone. Proc Natl Acad Sci USA 85:13121316.

Dutar P, Lamour Y, Nicoll RA (1989) Galanin blocks the slow cholinergic EPSP in CAl pyramidal neurons from ventral hippocampus. Eur J Pharmacol 164:355-360.

Ekblad E, Håkanson R, Sundler F, Wahlestedt C (1989) Galanin: neuromodulatory and direct contractile effects on smooth muscle preparations. Br J Pharmacol 86:241-246.

Fisone $\mathrm{G}, \mathrm{Wu} \mathrm{CF}$, Consolo $\mathrm{S}$, Nordström Ö, Brynne N, Bartfai $\mathrm{T}$, Melander T, Hökfelt T (1987) Galanin inhibits acetylcholine release in the ventral hippocampus of the rat: histochemical, autoradiographic, in vivo, and in vitro studies. Proc Natl Acad Sci USA 84:73397343.

Fisone G, Berthold M, Bedecs K, Unden A, Bartfai T, Bertorelli R, Consolo S, Crawley J, Martin B, Nilsson S, Hökfelt T (1989a) $\mathrm{N}$-terminal galanin-(1-16) fragment is an agonist at the hippocampal galanin receptor. Proc Natl Acad Sci USA 86:9588-9591.

Fisone G, Langel U, Carlquist M, Bergman T, Consolo S, Hökfelt T, Unden A, Andell S, Bartfai T (1989b) Galanin receptor and its ligands in the rat hippocampus. Eur J Biochem 181:269-276.

Fox JET, Brooks B, McDonald TJ, Barnett W, Kostolanska F, Yanaihara C, Yanaihara N, Rökaeus $\AA$ (1988) Actions of galanin fragments on rat, guinea-pig, and canine intestinal motility. Peptides 9: 1183-1189.

Fuxe K, von Euler G, Agnati LF, Ögren SO (1988) Galanin selectively modulates 5-hydroxytryptamine $1 \mathrm{~A}$ receptors in the rat ventral limbic cortex. Neurosci Lett 85:163-167.

Gabriel SM, MacGarvey UM, Koenig JI, Swartz KJ, Martin JB, Beal MF (1988) Characterization of galanin-like immunoreactivity in the rat brain: effects of nconatal glutamate treatment. Ncurosei Lett 87: 114-126.

Hermansen K, Yanaihara N, Ahren B (1989) On the nature of the galanin action on the endocrine pancreas: studies with six galanin fragments in the perfused dog pancreas. Acta Endocrinol 121:545550 .

Koshiyama $\mathrm{H}$, Kato $\mathrm{Y}$, Inoue $\mathrm{T}$, Murakami Y, Ishikawa Y, Yanaihara $\mathrm{N}$, Imura H (1987) Central galanin stimulates pituitary prolactin secretion in rats: possible involvement of hypothalamic vasoactive intestinal polypeptide. Neurosci Lett 7:49-54.

Kyrkouli SE, Stanley BG, Leibowitz SF (1986) Galanin: stimulation of feeding induced by medial hypothalamic injection of this novel peptide. Eur J Pharmacol 122:159-160.

Kyrkouli SE, Stanley BG, Leibowitz SF (1988) Galanin increases extracellular norepinephrine in the paraventricular hypothalamus as measured by microdialysis. Soc Neurosci Abstr 14:249.

Kyrkouli SE, Stanley BG, Hutchinson SR, Seirafi RD, Leibowitz SF (1990) Peptide-amine interactions in the hypothalamic paraventricular nucleus: analysis of galanin and neuropeptide $\mathrm{Y}$ in relation to feeding. Brain Res, in press.

Lagny-Pourmir I, Lorinet AM, Yanaihara N, Laburthe M (1989) Structural requirements for galanin interactions with receptors from pancreatic beta cells and from brain tissue of the rat. Peptides 10: $757-761$

Leonhardt U, Siegel EG, Köhler H, Barthel M, Tytko A, Nebendahl K, Creutzfeldt W (1989) Galanin inhibits glucose-induced insulin release in vitro. Horm Metab Res 21:100-101.

Mastropaolo J, Nadi NS, Ostrowski NL, Crawley JN (1988) Galanin antagonizes acetylcholine on a memory task in basal forebrain-lesioned rats. Proc Natl Acad Sci USA 85:9841-9845.

McDonald TJ, Dupre J, Tatemoto K, Greenberg GR, Rasziuk J, Mutt V (1985) Galanin inhibits insulin secretion and induces hyperglycemia in dogs. Diabetes 34:192-196.

Melander T, Hökfelt T, Rökaeus $\AA$ (1986) Distribution of galaninlike immunoreactivity in the rat central nervous system. J Comp Neurol 248:475-517.

Murakami $Y$, Kato $Y$, Koshiyama $H$, Inoue T, Yanaihara N, Imura $H$ (1987) Galanin stimulates growth hormone $(\mathrm{GH})$ secretion via $\mathrm{GH}$ releasing factor (GRF) in conscious rats. Eur J Pharmacol 136:415418 .

Nishibori M, Oishi R, Itoh Y, Saeki K (1988) Galanin inhibits noradrenaline-induced accumulation of cyclic AMP in the rat cerebral cortex. J Neurochem 51:1953-1955.

Nordström Ö, Melander T, Hökfelt T, Bartfai T, Goldstein M (1987) Evidence for an inhibitory effect of the peptide galanin on dopamine release from the rat medial eminence. Neurosci Lett 73:21-26.

Ögren SO, Fuxe K (1989) Intraventricular injections of galanin counteract development of head twitches induced by the 5-HT-2 agonist 1-(2,5-dimethoxyphenyl-4-bromo)-2-aminopropane. Acta Physiol Scand 136:297-298.

Ottlecz A, Snyder GD, McCann SM (1988) Regulatory role of galanin in control of hypothalamic-anterior pituitary function. Proc Natl Acad Sci USA 85:9861-9865. 
Palazzi E, Fisone G, Hökfelt T, Bartfai T, Consolo S (1988) Galanin inhibits the muscarinic stimulation of phosphoinositide turnover in rat ventral hippocampus. Eur J Pharmacol 148:479-480.

Paxinos G, Watson C. (1986) The rat brain in stereotaxic coordinates. New York: Academic.

Rökaeus $\AA$ (1987) Galanin: a newly isolated biologically active neuropeptidc. Trends Ncurosci 10:158-164.

Rossowski WJ, Coy DH (1989) Inhibitory action of galanin on gastric acid secretion in pentobarbital-anesthetized rats. Life Sci 44:18071813.

Seutin V, Verbanck P, Massotte L, Dresse A (1989) Galanin decreases the activity of locus coeruleus neurons in vitro. Eur J Pharmacol 164: 373-376.

Skofitsch G, Jacobowitz DM (1985) Immunohistochemical mapping of galanin-like neurons in the rat central nervous system. Peptides 6: 509-546.

Sundström E, Archer T, Melander T, Hökfelt T (1988) Galanin impairs acquisition but not retrieval of spatial memory in rats studied in the Morris swim maze. Neurosci Lett 88:331-335.
Tam JP (1985) A gradative deprotection strategy for the solid-phase synthesis of peptide amides using $p$-(acycloxy)benzhydrylamine resin and the $S_{N} 2$ deprotection method. J Org Chem 50:5291-5298.

Tam JP, Merrifield RB (1985) Solid phase synthesis of gastrin 1. Comparison of methods utilizing strong acid for deprotection and cleavage. Int J Pept Protein Res 26:262-273.

Tatcmoto K, Rökacus Å, Jörnvall H, McDonald TJ, Mutt V (1983) Galanin, a novel biologically active peptide from porcine intestine. FEBS Lett 164:124-128.

Tempel DL, Leibowitz KJ, Leibowitz SF (1988) Effects of PVN galanin on macronutrient selection. Peptides 9:309-314.

Tsuda K, Yokoo H, Goldstein M (1989) Neuropeptide Y and galanin in norepinephrine release in hypothalamic slices. Hypertension 14: $81-86$.

Wiesenfeld-Hallin Z, Villar MJ, Hökfelt T (1989) The effects of intrathecal galanin and C-fiber stimulation on the flexor reflex in the rat. Brain Res 486:205-213. 